\title{
PENINGKATAN KINERJA GURU DALAM MENYUSUN SILABUS DAN RPP MENGGUNAKAN MICROSOFT WORD MELALUI SUPERVISI AKADEMIK PENGAWAS DI MI BINAAN PRINGAPUS KABUPATEN SEMARANG
}

\author{
ADI HERMAWAN \\ Pengawas Madrasah Kementerian Agama Kabupaten Semarang \\ e-mail: : adihermawan68@gmail.com
}

\begin{abstract}
ABSTRAK
Pendidikan harus mampu membentuk manusia seutuhnya yang digambarkan sebagai manusia yang memiliki karakteristik personal yang memahami dinamika psikososial dan lingkungan kulturalnya. Proses pendidikan harus mencakup: (a) penumbuh kembangan keimanan, ketakwaan, (b) pengembangan wawasan kebangsaan, kenegaraan, demokrasi, dan kepribadian, (c) penguasaan ilmu pengetahuan dan teknologi, (d) pengembangan, penghayatan, apresiasi, dan ekspresi seni, serta (e) pembentukan manusia yang sehat jasmani dan rohani. Proses pembentukan manusia di atas pada hakekatnya merupakan proses pembudayaan dan pemberdayaan peserta didik yang berlangsung sepanjang hayat. Proses pendidikan yang dilaksanakan di atas tidak mungkin akan dapat tercapai kalau kinerja guru masih rendah terutama dalam membuat perencanan sekolah. Tujuan dari penelitian tindakan Kepengawasan ( PTKp ) ini adalah untuk mengetahui sejauh mana Peningkatan Kinerja Guru dalam menyusun Silabus dan RPP menggunakan Microsoft Word di MI Binaan Wilayah Kemenag Kec. Pringapus Kab. Semarang Tahun Pelajaran 2018/2019. Dalam penelitian tindakan Kepengawasan ( PTKp ) ini dilakukan dalam 3 siklus, dari hasil tindakan yang dilakukan terbukti dapat meningkatkan kinerja guru dalam menyusun Silabus dan RPP menggunakan Microsoft Word. Dari hasil rata-rata 59,09\% pada siklus I, dapat meningkat menjadi $70 \%$ pada siklus II, dan siklus ke III 85,45 \%.dan telah mencapai standar ideal, yaitu minimal $85 \%$, dan rata rata mencapai $100 \%$ ketuntasan. Hasil penelitian tindakan ini menunjukkan bahwa pembinaan pengawas melalui supervisi akademik efektif dan dapat meningkatan kinerja guru dalam menyusun Silabus dan RPP menggunakan Microsoft Word di SD Binaan Wilayah Kemenag Kec. Pringapus Kab. Semarang Tahun Pelajaran 2018-2019.
\end{abstract}

Kata Kunci : Peningkatan Kinerja Guru, Penyusunan Silabus dan RPP, Tinjauan tentang Microsoft Word, Supervisi Akademik Pengawas.

\section{ABSTRACT}

Education must be able to form a complete human being who is described as a human being who has personal characteristics who understand psychosocial dynamics and their cultural environment. The educational process must include: (a) the development of faith, piety, (b) the development of national, state, democratic, and personality insights, (c) mastery of science and technology, (d) development, appreciation, appreciation, and artistic expression, and (e) the formation of physically and mentally healthy human beings. The process of human formation above is essentially a process of cultivating and empowering students that lasts a lifetime. The educational process carried out above is unlikely to be achieved if teacher performance is still low, especially in making school planning. The purpose of this supervisory action research (PTKp) is to find out the extent to which teacher performance improvement in compiling the syllabus and lesson plans using Microsoft Word in MI assisted by the Ministry of Religion, Kec. Pringapus Kab. Semarang Academic Year 2018/2019. In this supervisory action research (PTKp) it was carried out in 3 cycles, from the results of the actions taken it was proven to be able to improve teacher performance in compiling syllabus and lesson plans using Microsoft Word. From the average results of $59.09 \%$ in the first cycle, it can increase to $70 \%$ in the second cycle, and $85.45 \%$ in the third cycle. And it has reached the ideal standard, which is at least $85 \%$, and the average reaches $100 \%$ completeness. The results of this action research indicate that the supervision of supervisors through academic supervision is effective and can improve 
teacher performance in compiling the Syllabus and lesson plans using Microsoft Word at the Ministry of Religion's Regional Assisted Elementary Schools, Kec. Pringapus Kab. Semarang Academic Year 2016-2017.

Keywords: Improving Teacher Performance, Preparation of Syllabus and Lesson Plans, Overview of Microsoft Word, Academic Supervision of Supervisors.

\section{PENDAHULUAN}

Istilah kinerja dapat diterjemahkan dalam perfomance atau unjuk kerja, artinya kemampuan yang ditampilkan seseorang terhadap pekerjaannya pada tempat ia bekerja. Kinerja merupakan suatu kinerja yang esensial terhadap keberhasilan suatu pekerjaan. Karena itu suatu kinerja yang efektif bagi setiap individu perli diciptakan sehingga tujuan lembaga dapat tercapai secara optimal.

Lebih lanjut Hamalik (2002) kemampuan dasar yang disebut juga kinerja dari seorang guru teridiri dari: (1) kemampuan merencanakan pembelajaran, (2) kemampuan mengelola program belajar mengajar, (3) kemampuan menglola kelas (4) kemampuan menggunakan media/sumber belajar, (5) kemampuan mengelola interaksi belajar mengajar, (6) mampu melaksanakan evaluasi belajar siswa.

Evaluasi kinerja guru mutlak dilakukan, karena masih terdapat banyak kinerja guru yang kurang memadai, disamping itu guru dituntut dapat mengikuti perkembangan ilmu pengetahuan, teknologi dan seni yang terus berkembang pula dengan pesat. Istilah kinerja berasal dari bahasa inggris yaitu Performance, berarti hasil kena atau unjuk kerja yang dicapai seseorang atau sekelompok orang/organisasi tertentu. Istilah kinerja dapat diterjemahkan dalam unjuk kerja, artinya kemampuan yang ditampilkan seseorang terhadap pekerjaannya di tempat ia bekerja. Kinerja merupakan suatu hal yang sangat esensial terhadap keberhasilan suatu pekerjan. Pada hakikatnya orang bekerja untuk memenuhi kebutuhan atas dorongan tertentu. Kebutuhan dipandang sebagai penggerak atau pembangkit perilaku, sedanghkan tujuannya berfungsi untuk menggerakkan perilaku. Karena itu suatu kinerja yang efektif bagi setiap individu, perlu disiptakan sehingga tujuan lembaga dapat tercapai secara optimal.

Pendidikan agama Islam merupakan bagian dari pendidikan Islam. Pendidikan Islam merupakan subsistem pendidikan nasional dan ini sesuai dengan UU No. 2, tahun 1989, tentang pendidikan nasional (Maksudin:2004). Pelaksanaan pendidikan agama Islam di pendidikan formal atau sekolah mempunyai dasar-dasar yang sangat kuat, dan ini dapat ditinjau dari beberapa segi, yaitu dasar yuridis, dasar religius, dan dasar psikologis.

Proses pendidikan yang dilaksanakan di atas tidak mungkin akan dapat tercapai kalau kinerja guru masih rendah terutama dalam membuat perencanan sekolah.Seberapapun kemampuan Pengawas dalam membuat perencanaan seklah tapi kalu tidak ditunjang oleh kemampuan kguru dalam membuat perencanaan pembelajaran,mustahil mutu pendidikan dapat ditingkatkan.

Salah satu upaya peningkatan kemampuan guru adalah dalam membuat perencanaan pembelajaran yang telah digariskan dalam kurikulum. Perencanaan pembelajaran merupakan kegiatan yang harus dilakukan oleh seorang guru, karena merupakan kegiatan menetapkan halhal yang harus dilakukan agar proses pembelajaran berlangsung dengan baik. Perencanaan pembelajaran yang mendidik perlu mengikuti prosedur yang tepat agar rencana tersebut sesuai dengan aturan yang berlaku dan sesuai dengan teori belajar dan pembelajaran. Badan Standar Nasional Pendidikan (BSNP), dalam pedoman penyusunan KTSP mengemukakan langkahlangkah yang ditempuh dalam pengembangan silabus mata pelajaran adalah (1) mengkaji standar kompetensi dan kompetensi dasar, (2) mengidentifikasi materi pokok pembelajaran, (3) mengembangkan kegiatan pembelajaran, (4) merumuskan indikator pencapaian kompetensi, (5) menetapkan jenis penilaian berdasarkan indikator pencapaian kompetensi, (6) menentukan alokasi waktu tiap kegiatan pembelajaran, dan (7) menentukan sumber belajar.

Untuk mendapatkan perencanaan pembelajaran yang baik maka kepada semua guru dan stakeholder perlu diberikan pembinaan dan bimbingan dari Pengawas yang dilaksanakan 
melalui pelatihan maupun lokakarya yang diselenggrakan oleh sekolah agar tujuan pendidikan dapat dicapai.

Perangkat pembelajaran adalah perangkat yang dipergunakan selama proses pembelajaran. Perangkat pembelajaran yang digunakan untuk mengelola pembelajaran meliputi Buku Siswa, Silabus, Rencana Pelaksanaan Pembelajaran (RPP), Lembar Kegiatan Siswa (LKS), Instrumen Evaluasi atau Tes Hasil Belajar (TBH), serta Media Pembelajaran (Ibrahim dalam Trianto, 2010: 96). Silabus berasal dari bahasa latin "Syllabus" yang berarti daftar, tulisan, ikhtisar, ringkasan, isi buku (Komaruddin, 2000). Silabus digunakan untuk menyebut suatu produk pengembangan kurikulum berupa penjabaran lebih lanjut dari standar kompetensi dan kemampuan dasar yang ingin dicapai, dan pokok-pokok serta uraian materi yang perlu dipelajari peserta didik dalam mencapai standar kompetensi dan kompetensi dasar. Rencana Pelaksanaan Pembelajaran (RPP) adalah rencana yang menggambarkan prosedur, dan pengorganisasian pembelajaran untuk mencapai satu kompetensi dasar yang ditetapkan. Dalam standar isi yang telah dijabarkan dalam silabus. Ruang lingkup rencana pembelajaran paling luas mencakup 1 (satu) kompetensi dasar yang terdiri atas 1 (satu) atau beberapa indikator untuk 1 (satu) kali pertemuan atau lebih.

Sehubungan dengan hal di atas maka penulis perlu melakukan penelitian tindakan dalam upaya meningkatkan kinerja guru yang dilaksanakan melalui kegiatan pelatihan dengan judul : "Peningkatan Kinerja Guru dalam Menyusun Silabus dan RPP menggunakan Microsoft Word melalui Supervisi Akademik Pengawas di MI Binaan Wilayah Kemenag Kec. Pringapus Kabupaten Semarang Tahun Pelajaran 2018/ 2019”.

\section{METODE PENELITIAN}

Penelitian ini merupakan penelitian tindakan kepengawasan, yaitu pencermatan terhadap kegiatan kepengawasan berupa sebuah tindakan, yang sengaja dimunculkan dan terjadi dalam satu madrasah binaan. Dalam pelaksanaannya peneliti dapat melakukan penelitian tindakan kepengawasan secara mandiri maupun kolaboratif partisifatif, akan tetapi tidak boleh menghambat kegiatan utama Kepala Madrasah dalam melaksanakan tugas dan tanggung jawabnya (Arikunto, 2008).

Subyek dalam penelitian tindakan kepengawasan ini adalah MI Binaan Wilayah Kemenag Kec. Pringapus Kabupaten Semarang Tahun Pelajaran 2018/ 2019. Setting dalam pelaksanaan ini sebagai berikut PTKp dilakukan pada MI Binaan Wilayah Kemenag Kecamatan Pringapus Kabupaten Semarang Tahun Pelajaran 2019/2020. Guru MI Binaan Wilayah Kemenag Kec. Pringapus Kabupaten Semarang yang hadir pada saat penelitian ini dilakukan terdiri dari 11 orang. PTKp dilakukan pada guru MI Binaan Wilayah Kemenag Kecamatan Pringapus Kabupaten Semarang. Dalam penelitian Tindakan Kepengawasan ( PTKp ) ini variabel yang diteliti adalah Peningkatan Kinerja Guru MI dalam menyusun Silabus dan RPP menggunakan Microsoft Word melalui supervisi Akademik Pengawas.

\section{HASIL DAN PEMBAHASAN \\ Hasil \\ Siklus I}

Pelaksanaan kegiatan pembinaan untuk siklus I dilaksanakan pada tanggal 20 - 31 Januari 2020, di MI Binaan Wilayah Kemenag Kec. Pringapus Kabupaten Semarang tahun pelajaran 2018/ 2019. Dalam hal ini peneliti bertindak sebagai Pengawas. Adapun proses pembinaan mengacu pada rencana pembinaan yang telah dipersiapkan. Pengamatan (observasi) dilaksanakan bersamaan dengan pelaksanaan pembelajaran. Pada akhir proses pembinaan guru diberi penilaian formatif I dengan tujuan untuk mengetahui tingkat pemahaman guru dalam meningkatkan kinerja dalam menyusun Silabus dan RPP menggunakan Microsoft Word sesuai dengan rencana yang telah dilakukan. Adapun data hasil penelitian pada siklus I. adalah seperti pada tabel berikut : 
Tabel 1.Tabel Hasil Peningkatan Kinerja Guru dalam Menyusun Silabus dan RPP menggunakan Microsoft Word Pada Siklus I.

\begin{tabular}{|c|c|c|c|}
\hline NO & Nama Guru & Nilai & Keterangan \\
\hline 1 & Umi Halimah Saadah, M.S.I & 60 & Tidak Tuntas \\
\hline 2 & Ambar Munifah, S.Pd.I & 50 & Tidak Tuntas \\
\hline 3 & Rohmah, S.Pd.I & 75 & Tuntas \\
\hline 4 & Siti Maslahah, S.Pd I & 45 & Tidak Tuntas \\
\hline 5 & Priyanto, S.Pd I & 55 & Tidak Tuntas \\
\hline 6 & Samsul Khoeri, S.Pd I & 80 & Tuntas \\
\hline 7 & Moh Sholihun, S.Pd & 45 & Tidak Tuntas \\
\hline 8 & Siti Umi Andari, S.Pd & 50 & Tidak Tuntas \\
\hline 9 & Lailatul Munifah, S.Pd & 60 & Tidak Tuntas \\
\hline 10 & Abdul Kholiq, S.Pd.I. & 50 & Tidak Tuntas \\
\hline 11 & Nur Mahmudah, A.Ma. & 65 & Tidak Tuntas \\
\hline 12 & Susiyanti,S.Pd. & 50 & Tidak Tuntas \\
\hline \multicolumn{2}{|r|}{ Jumlah Total } & 685 & - \\
\hline \multicolumn{2}{|r|}{ Skor Maksimum } & 100 & - \\
\hline \multicolumn{2}{|r|}{ Skor Maksimum Kelompok } & 1200 & - \\
\hline
\end{tabular}

Keterangan :

Jumlah Guru yang tuntas

Jumlah Guru yang belum tuntas

Kelompok (Sekolah)

$$
\begin{aligned}
& : 2 \text { Orang } \\
& : 10 \text { Orang } \\
& : \text { Belum Tuntas. }
\end{aligned}
$$

Dari tabel di atas dapat dijelaskan bahwa dengan pembinaan yang dilakukan oleh Pengawas melalui penyususnan Silabus dan RPP menggunakan Microsoft Word diperoleh nilai rata-rata Peningkatan Kinerja Guru MI adalah 57,08 \% atau baru 2 dari 12 orang guru yang sudah tuntas. Hasil tersebut menunjukkan bahwa pada siklus pertama secara kelompok ( sekolah ) belum meningkat mutunya dalam menyusun Silabus dan RPP menggunakan Microsoft Word , karena yang memperoleh nilai $\geq 75$ hanya sebesar 16,67 \% lebih kecil dari persentase ketuntasan yang dikehendaki yaitu sebesar $75 \%$. Hal ini disebabkan karena banyak guru yang belum memahami dan merasa baru dengan dalam menyusun Silabus dan RPP menggunakan Microsoft Word sehingga mereka belum dapat memahaminya dengan baik.

\section{Siklus II}

Pelaksanaan kegiatan pembinaan melalui penyususnan Silabus dan RPP menggunakan Microsoft Word untuk siklus II dilaksanakan pada tanggal 3 - 15 Pebruari 2020 di MI Binaan Wilayah Kemenag Kec. Pringapus Kabupaten Semarang Tahun Pelajaran 2018/ 2019. Dalam hal ini peneliti bertindak sebagai Pengawas. Adapun proses pembinaan mengacu pada rencana pembinaan dengan memperhatikan revisi pada siklus I, sehingga kesalahan atau kekurangan pada siklus I tidak terulang lagi pada siklus II. Penelitian tindakan kepengawasan ini dilaksanakan sesuai dengan prosedur rencana pembinaan dan skenario pembinaan, serta kegiatan pembinaan dilaksanakan pada saat proses pembelajaran berlangsung.

Pada akhir proses pembinaan guru diberi tes formatif II dengan tujuan untuk mengetahui tingkat kinierja guru melakukan evaluasi hasil belajar. Instrumen yang digunakan adalah tes formatif II. Adapun data hasil penelitian pada siklus II adalah sebagai berikut 
Tabel 2. Tabel Hasil Peningkatan Kinerja Guru dalam menyusun Silabus dan RPP menggunakan Microsoft Word Pada Siklus II

\begin{tabular}{|c|c|c|c|}
\hline NO & Nama Guru & Nilai & Keterangan \\
\hline 1 & Umi Halimah Saadah, M.S.I & 75 & Tuntas \\
\hline 2 & Ambar Munifah, S.Pd.I & 60 & Tidak Tuntas \\
\hline 3 & Rohmah, S.Pd.I & 85 & Tuntas \\
\hline 4 & Siti Maslahah, S.Pd I & 60 & Tidak Tuntas \\
\hline 5 & Priyanto, S.Pd I & 75 & Tuntas \\
\hline 6 & Samsul Khoeri, S.Pd I & 80 & Tuntas \\
\hline 7 & Moh Sholihun, S.Pd & 60 & Tidak Tuntas \\
\hline 8 & Siti Umi Andari, S.Pd & 75 & Tuntas \\
\hline 9 & Lailatul Munifah, S.Pd & 75 & Tuntas \\
\hline 10 & Abdul Kholiq, S.Pd.I. & 60 & Tidak Tuntas \\
\hline 11 & Nur Mahmudah, A.Ma. & 65 & Tidak Tuntas \\
\hline 12 & Susiyanti,S.Pd. & 80 & Tuntas \\
\hline \multicolumn{2}{|r|}{ "Jumlah Total } & 850 & - \\
\hline \multicolumn{2}{|r|}{ Skor Maksimum } & 100 & - \\
\hline \multicolumn{2}{|r|}{ Skor Maksimum Kelompok } & 1200 & - \\
\hline
\end{tabular}

Keterangan :

Jumlah Guru yang tuntas $\quad: 7$ orang

Jumlah Guru yang belum tuntas : $: 5$ orang

Kelompok (Sekolah)

: Belum Tuntas.

Dari tabel di atas diperoleh nilai rata-rata Peningkatan Kinerja Guru MI dalam menyusun Silabus dan RPP menggunakan Microsoft Word adalah 70,83\% dan peningkatan mutu mencapai $58,33 \%$ atau sudah 7 orang dari 12 orang guru yang sudah tuntas meningkatkan mutunya dalam membuat silabus dan RPP 1 Lembar. Hasil ini menunjukkan bahwa pada siklus II ini Peningkatan Kinerja Guru MI telah mengalami peningkatan sedikit lebih baik dari siklus I. Adanya peningkatan ini karena setelah Pengawas menginformasikan bahwa setiap akhir pembinaan diadakan penilaian sehingga pada pertemuan berikutnya guru lebih termotivasi untuk meningkatkan kinerjanya. Selain itu guru juga sudah mulai mengerti apa yang dimaksudkan dan diinginkan oleh Pengawas dalam melakukan pembinaan supervisi Pengawas.

\section{Siklus III}

Pelaksanaan kegiatan belajar mengajar untuk siklus III dilaksanakan pada tanggal 17 24 Pebruari 2020 di MI Binaan Wilayah Kemenag Kec. Pringapus Kabupaten Semarang tahun pelajaran 2018/ 2019 dengan jumlah 12 orang guru. Dalam hal ini peneliti bertindak sebagai Pengawas. Adapun proses pembinaaan mengacu pada rencana pembinaan dengan memperhatikan revisi pada siklus II, sehingga kesalahan atau kekurangan pada siklus II tidak terulang lagi pada siklus III. Pengamatan (observasi) dilaksanakan bersamaan dengan pelaksanaan proses belajar mengajar berlangsung.

Pada akhir proses pembinaan guru diberi penilaian formatif III dengan tujuan untuk mengetahui tingkat capaian kinerja guru dalam menyusun Silabus dan RPP menggunakan Microsoft Word yang telah dilakukan. Instrumen yang digunakan adalah tes formatif III. Adapun data hasil penelitian pada siklus III adalah sebagai berikut : 
Tabel 3. Tabel Hasil Peningkatan kinerja guru dalam menyusun Silabus dan RPP menggunakan Microsoft Word Pada Siklus III

\begin{tabular}{||c||l||c||c|}
\hline NO & \multicolumn{1}{|c||}{ Nama Guru } & Nilai & Keterangan \\
\hline \hline 1 & Umi Halimah Saadah, M.S.I & 90 & Tuntas \\
\hline 2 & Ambar Munifah, S.Pd.I & 80 & Tuntas \\
\hline 4 & Rohmah, S.Pd.I & 90 & Tuntas \\
\hline 5 & Siti Maslahah, S.Pd I & 80 & Tuntas \\
\hline 6 & Priyanto, S.Pd I & 85 & Tuntas \\
\hline 7 & Samsul Khoeri, S.Pd I & 90 & Tuntas \\
\hline 8 & Moh Sholihun, S.Pd & 80 & Tuntas \\
\hline 9 & Siti Umi Andari, S.Pd & 90 & Tuntas \\
\hline 10 & Abilatul Munifah, S.Pd & 85 & Tuntas \\
\hline 11 & Nur Mahmudah, A.Ma. & 80 & Tuntas \\
\hline 12 & Susiyanti,S.Pd. & 90 & Tuntas \\
\hline \hline \multicolumn{2}{|c||}{ Jumlah Total } & $\mathbf{1 0 2 0}$ & Tuntas \\
\hline \hline \multicolumn{2}{|c|}{ Skor Maksimum } & $\mathbf{1 0 0}$ & - \\
\hline \hline \multicolumn{2}{|c|}{ Skor Maksimum Kelompok } & $\mathbf{1 2 0 0}$ & - \\
\hline
\end{tabular}

Keterangan :

Jumlah Guru yang tuntas

Jumlah Guru yang belum tuntas

Kelompok (Sekolah)
: 12 orang

: - Orang

: Sudah tuntas.

Berdasarkan tabel di atas diperoleh nilai rata-rata tes formatif sebesar 85,00\% dan dari 12 orang guru secara keseluruhan sudah mencapai ketuntasan dalam meningkatkan kinerja guru dalam menyusun Silabus dan RPP menggunakan Microsoft Word . Maka secara kelompok ketuntasan telah mencapai $100 \%$ ( termasuk kategori tuntas ). Hasil pada siklus III ini mengalami peningkatan sangat baik dari siklus II. Adanya Peningkatan Kinerja Guru MI dalam menyusun Silabus dan RPP menggunakan Microsoft Word pada siklus III ini dipengaruhi oleh adanya peningkatan kemampuan Pengawas dalam menerapkan pembinaan melalui penyususnan Silabus dan RPP menggunakan Microsoft Word sehingga guru menjadi lebih memahami tugasnya sehingga dapat meningkatkan kinerja guru. Di samping itu ketuntasan ini juga dipengaruhi oleh kerja sama dari guru dengan Pengawas dalam melaksanakan tugasnya masing masing.

\section{Analisis Hasil Kegiatan}

Setelah dilakukan tindakan pada siklus 1 , siklus 2 dan siklus 3 menunjukkan hasil sebagai berikut.

Tabel 4. Analisis Hasil Peningkatan Kinerja Guru MI menyusun Silabus dan RPP menggunakan Microsoft Word

\begin{tabular}{|c|l|c|c|c|}
\hline No & \multicolumn{1}{|c|}{ Nama } & $\begin{array}{c}\text { Skor sebelum } \\
\text { Tindakan } \\
\text { Siklus 1 }\end{array}$ & $\begin{array}{c}\text { Skor setelah } \\
\text { Tindakan 1 } \\
\text { Siklus 2 }\end{array}$ & $\begin{array}{c}\text { Skor setelah } \\
\text { Tindakan 2 } \\
\text { Siklus 3 }\end{array}$ \\
\hline 1 & Umi Halimah Saadah, M.S.I & 60 & 75 & 90 \\
\hline 2 & Ambar Munifah, S.Pd.I & 50 & 60 & 80 \\
\hline 3 & Rohmah, S.Pd.I & 75 & 85 & 90 \\
\hline 4 & Siti Maslahah, S.Pd I & 45 & 60 & 80 \\
\hline
\end{tabular}




\begin{tabular}{|c|l|c|c|c|}
\hline 5 & Priyanto, S.Pd I & 55 & 75 & 85 \\
\hline 6 & Samsul Khoeri, S.Pd I & 80 & 80 & 90 \\
\hline 7 & Moh Sholihun, S.Pd & 45 & 60 & 80 \\
\hline 8 & Siti Umi Andari, S.Pd & 50 & 75 & 90 \\
\hline 9 & Lailatul Munifah, S.Pd & 60 & 75 & 85 \\
\hline 10 & Abdul Kholiq, S.Pd.I. & 50 & 60 & 80 \\
\hline 11 & Nur Mahmudah, A.Ma. & 65 & 65 & 90 \\
\hline 12 & Susiyanti,S.Pd. & 50 & 80 & 80 \\
\hline Jumlah Total & $\mathbf{6 8 5}$ & $\mathbf{8 5 0}$ & $\mathbf{1 0 2 0}$ \\
\hline Skor Maksimum & $\mathbf{1 0 0}$ & $\mathbf{1 0 0}$ & $\mathbf{1 0 0}$ \\
\hline \multicolumn{2}{|l|}{ Skor Maksimum Kelompok } & $\mathbf{1 2 0 0}$ & $\mathbf{1 2 0 0}$ & $\mathbf{1 2 0 0}$ \\
\hline
\end{tabular}

Analisis Data Deskriptif Kuantitatif

1. Pencapaian peningkatan kenerja guru dalam menyusun Silabus dan RPP menggunakan Microsoft Word sebelum diberi tindakan oleh Pengawas ; $\frac{685}{1200} \times 100 \%=57,08 \%$

2. Pencapaian peningkatan kenerja guru dalam menyusun Silabus dan RPP menggunakan Microsoft Word setelah diberi tindakan $\frac{850}{1200} \times 100 \%=70,83 \%$

3. Pencapaian peningkatan kenerja guru dalam menyusun Silabus dan RPP menggunakan Microsoft Word setelah diberi tindakan $\frac{1020}{1200} \times 100 \%=85,00 \%$

Dari tabel diatas dapat disajikan grafik sebagai berikut untuk mengetahui peningkatan setiap siklus.

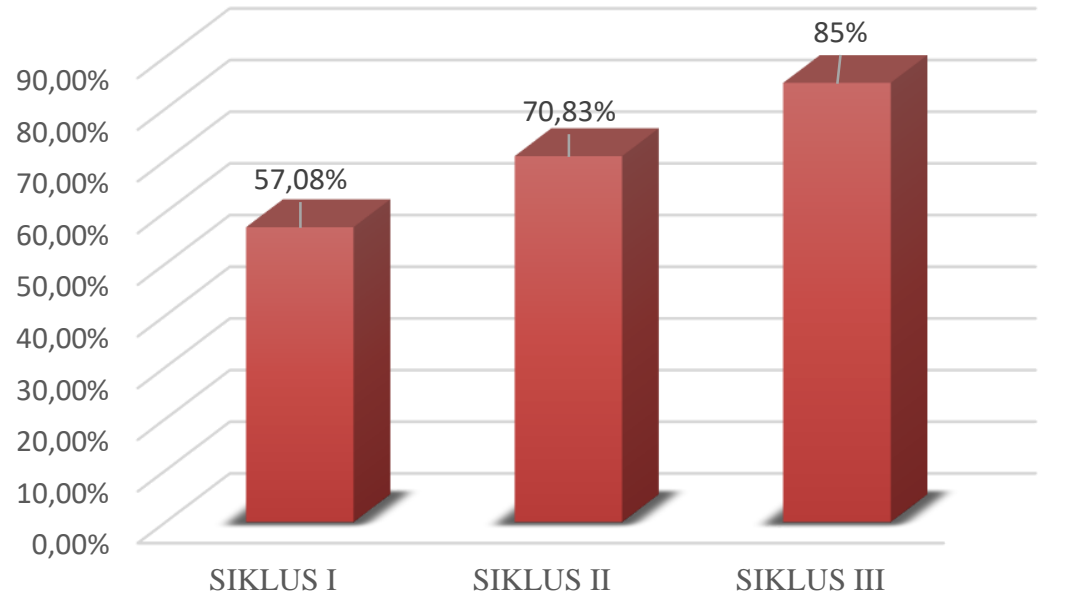

Gambar 1. Perbadingan hasil Siklus I, Siklus II, dan Siklus III

Dari hasil analisis grafik tersebut dapat disimpulkan bahwa

1. Terjadi peningkatan kenerja guru dalam menyusun Silabus dan RPP menggunakan Microsoft

Word setelah diberi $57,08 \%$ menjadi $70,83 \%$ ada kenaikan sebesar $=13,75 \%$

2. Dari sebelum pembinaan (siklus 1) $57,08 \%$ dan setelah pembinaan oleh Pengawas (siklus 2) $70,83 \%$, sampai dengan (siklus 3) menjadi dan dari (siklus 2) ke (siklus 3) 85,00\% juga ada peningkatan sebanyak $85,00 \%-70,83 \%=14,17 \%$.

3. Rata-rata peningkatan kenerja guru mulai dari sebelum diberi pembinaan sampai selesai melaksanaan pembinaan siklus III naik dari 57,08\% menjadi $100 \%$

\section{Pembahasan}

1. Ketuntasan Hasil Pembinaan Kepada Guru.

Melalui hasil penelitian ini menunjukkan bahwa pembinaan melalui penyususnan Silabus dan RPP menggunakan Microsoft Word memiliki dampak positif meningkatkan kenerja guru, hal ini dapat dilihat dari semakin mantapnya pemahaman guru dan terhadap 
pembinaan yang disampaikan Pengawas (kinerja guru dalam menyusun Silabus dan RPP menggunakan Microsoft Word meningkat dari siklus I, II, dan III ) yaitu masing-masing 59,09 $\%$; $70 \%$; 85,45 \% Pada siklus III Peningkatan Kinerja Guru MI dalam menyusun Silabus dan RPP menggunakan Microsoft Word secara kelompok dikatakan tuntas (100\% tuntas).

2. Kemampuan Pengawas meningkatkan kinerja guru dalam menyusun Silabus dan RPP menggunakan Microsoft Word ;

Berdasarkan analisis data, diperoleh aktivitas guru dalam meningkatkan kinerja guru pada setiap siklus mengalami peningkatan. Hal ini berdampak positif terhadap mutu sekolah, yaitu dapat ditunjukkan dengan meningkatnya nilai rata-rata guru pada setiap siklus yang terus mengalami peningkatan.

3 Aktivitas Pengawas dalam Pembinaan melalui penyususnan Silabus dan RPP menggunakan Microsoft Word ;

Berdasarkan analisis data, diperoleh aktivitas guru, yang paling dominan dalam kegiatan supervisi Pengawas adalah bekerja dengan menggunakan alat/media, mendengarkan atau memperhatikan penjelasan Pengawas, dan diskusi antar guru dan Pengawas. Jadi dapat dikatakan bahwa aktivitas guru dapat dikategorikan aktif.

Sedangkan untuk aktivitas Pengawas selama pembinaan telah melaksanakan langkahlangkah metode pembinaan melalui penyususnan Silabus dan RPP menggunakan Microsoft Word dengan baik. Hal ini terlihat dari aktivitas guru yang muncul di antaranya aktivitas membuat dan merencanakan program sekolah, melaksanakan, memberi umpan balik/evaluasi/tanya jawab di mana persentase untuk aktivitas di atas cukup besar.

Berdasarkan hasil penelitian di atas, Peningkatan Kinerja Guru MI dalam menyusun Silabus dan RPP menggunakan Microsoft Word hasilnya sangat baik. Hal itu tampak pada pertemuan pertama dari 12 orang guru yang ada pada saat penelitian ini dilakukan nilai rata rata mencapai ; 57,08 \% meningkat menjadi 70,83\% dan pada siklus 3 meningkat menjadi 85,00\%

Dari analisis data di atas bahwa pembinaan guru oleh Pengawas melalui melalui penyususnan Silabus dan RPP menggunakan Microsoft Word efektif diterapkan dalam upaya meningkatkan capaian kinerja guru, yang berarti proses pembinaan Pengawas lebih berhasil dan dapat meningkatkan kinerja guru, khususnya MI Binaan Wilayah Kemenag Kec. Pringapus Kabupaten Semarang, oleh karena itu diharapkan kepada para Pengawas dapat melaksanakan pembinaan melalui penyususnan Silabus dan RPP menggunakan Microsoft Word.

Berdasarkan Permen No 12 Tahun 2007 tentang kompetensi guru dan Pengawas, dan dapat membuat rencana kerja sekolah, serta dapat mengorganisasikan sekolah kearah perubahan yang diinginkan mencapai $85 \%$ ketercapaiannya, maka penyususnan Silabus dan RPP menggunakan Microsoft Word tersebut dikatakan efektif. Dengan demikian maka hipotesis yang diajukan di atas dapat diterima.

Hal ini diperkuat dengan adanya penelitian yang terdahulu oleh Susetya (2017) yang berjudul Meningkatkan Kemampuan Guru Dalam Menyusun Silabus Dan Rpp Melalui Supervisi Akademik di SDN Gambiran Yogyakarta didapatkan hasil bahwa Pelaksanaan supervisi individual sangat cocok digunakan untuk meningkatkan kompetensi guru dalam menyusun silabus dan RPP yang selama ini masih menjadi administrasi yang masih sulit diminta dari guru-guru.

\section{KESIMPULAN}

Penelitian ini adalah model pembinaan melalui penyususnan Silabus dan RPP menggunakan Microsoft Word kepada guru di MI Binaan Wilayah Kemenag Kec. Pringapus Kabupaten Semarang, dalam upaya Peningkatan Kinerja Guru MI. Penerapan Penyususnan Silabus dan RPP menggunakan Microsoft Word dilaksanakan secara efektif baik oleh Pengawas maupun oleh guru. Secara keseluruhan penerapan Penyususnan Silabus dan RPP menggunakan Microsoft Word ini dapat meningkatkan kinerja guru. Peningkatan Kinerja Guru MI dalam menyusun Silabus dan RPP menggunakan Microsoft Word menunjukan peningkatan 
pada tiap-tiap siklusnya (Siklus I, 57,08 \% ; siklus II, 70,83 \% ; Siklus III, 85,00 \%). Aktivitas guru menunjukan bahwa pembinaan melalui penyususnan Silabus dan RPP menggunakan Microsoft Word bermanfaat dan dapat membantu guru untuk lebih muda memahami konsep yang diberikan sehingga kinerja guru meningkat, dan capaian mutu sekolah dapat ditingkatkan.

\section{DAFTAR PUSTAKA}

Abdul Majid. (2004). Pendidikan Agama Islam Berbasis Kompetensi: Konsep dan Implementasi Kurikulum. Bandung: Remaja RoMIaKarya

Arikunto, Suharsimi. (2008). Penelitian Tindakan Kelas. Jakarta: Bumi Aksara

Hamalik, O. (2002). Perencanaan Pengajaran Berdasarkan Pendekatan Sistem. Jakarta: PT. Bumi Aksara

Komaruddin. (2000). Manajemen Pengawasan Kualitas Terpadu. Jakarta: Rajawali.

Maksudin. (2004). Pengembangan Metodologi Pendidikan Agama Islam Di SMU. Yogyakarta: LESFI

Mulyasa, E. (2004). Menjadi Guru professional. Bandung: PT. Remaja Rosdakarya,

Munir, Abdullah. (2008). Menjadi Kepala Sekolah Efektif. Yogyakarta: ArRuzz Media.

Peraturan Menteri Pendidikan Nasional Nomor 13 Tahun 2007 tentang Standar Kepala Sekolah/Madrasah

Slameto. (2010). Belajar dan Faktor-Faktor yang Mempengaruhi. Jakarta: Rineka Cipta

Susetya, Beny. (2017). Meningkatkan Kemampuan Guru Dalam Menyusun Silabus Dan Rpp

Melalui Supervisi Akademik Di Sd N Gambiran Yogyakarta Tahun 2016. Jurnal Taman Cendekia, Vol. 01 No. 02

Susilo. (2007). Panduan Penelitian Tindakan Kelas. Yogyakarta: Pustaka Book Publlisher

Trianto. (2010). Model Pembelajaran Terpadu, Konsep, Strategi dan Implementasinya dalam KTSP. Jakarta: Bumi Aksara 